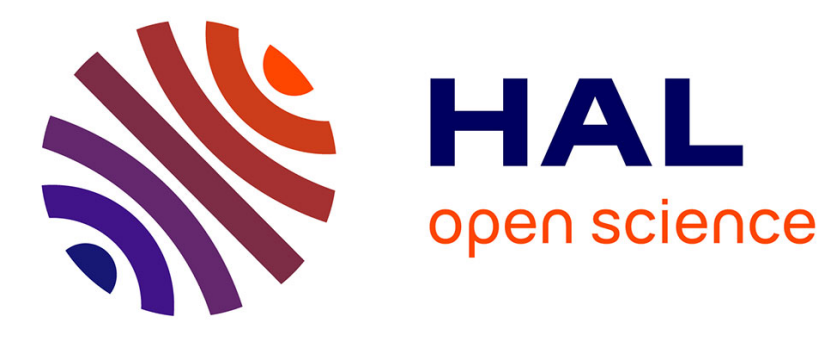

\title{
Controlling the acoustic resonance in a corrugated flow pipe.
}

Muriel Amielh, Fabien Anselmet, Yan Jiang, Ulf R. Kristiansen, Pierre-Olivier Mattei, Daniel Mazzoni, Cédric Pinhède

\section{- To cite this version:}

Muriel Amielh, Fabien Anselmet, Yan Jiang, Ulf R. Kristiansen, Pierre-Olivier Mattei, et al.. Controlling the acoustic resonance in a corrugated flow pipe.. "Fluid-Structure-Sound Interactions and Control". Proceedings of the 2nd Symposium on Fluid-Structure. Zhou, Y.; Liu, Y.; Huang, L.; Hodges, D.H. (Eds.)., Springer-Verlag, pp.253-258, 2014. hal-01024709

\section{HAL Id: hal-01024709 https://hal.science/hal-01024709}

Submitted on 18 Feb 2016

HAL is a multi-disciplinary open access archive for the deposit and dissemination of scientific research documents, whether they are published or not. The documents may come from teaching and research institutions in France or abroad, or from public or private research centers.
L'archive ouverte pluridisciplinaire HAL, est destinée au dépôt et à la diffusion de documents scientifiques de niveau recherche, publiés ou non, émanant des établissements d'enseignement et de recherche français ou étrangers, des laboratoires publics ou privés. 


\title{
Controlling the acoustic resonance in a corrugated flow pipe
}

\author{
M. Amielh ${ }^{1}$, F. Anselmet ${ }^{1,2}$, Y. Jiang ${ }^{3}$, U. Kristiansen ${ }^{3}$, P.O. Mattéi ${ }^{4}$, D. \\ Mazzoni' $^{2,4}$, C. Pinhède ${ }^{4}$
}

\begin{abstract}
A new experimental set-up, aimed at investigating the coupling between the flow in a corrugated pipe, the acoustically generated flow oscillations and the emitted resulting noise is carried out. Hot-wire anemometry and microphone measurements are associated to characterize the flow. The flow response to the corrugation is shown to fit to the $6^{\text {th }}$ to $9^{\text {th }}$ acoustic modes of the pipe according to the flow rate. When low frequency acoustically generated oscillations interfere with this, one checks that they either significantly reduce the noise level or modify the peak frequencies. In addition, theoretical/numerical works are also performed, in order to provide an analytical framework describing the acoustical properties of such corrugated pipe flows.
\end{abstract}

Keywords: corrugated pipe - acoustic control - turbulent flow

\section{Introduction}

Our study is focused on a phenomenon often encountered in flow carrying pipes, since flow instabilities caused by geometric features may generate acoustic signals and thereafter interact with these signals in such a way that powerful pure tones are produced. Classic examples of flow generated tones are the Aeolian tones heard when a cylinder is put in an air flow, and the tone heard when blowing across the opening of a bottle. In industrial applications such tones may be powerful and, in addition to being annoying, damage machinery due to induced vibrations.

A modern example is found in the so-called "singing risers", or the gas pipes connecting gas production platforms to the transport network. These pipes can be very long, i.e. hundred of meters, and are constructed in such a way that on the inside there is a periodic arrangement of cavities (corrugated pipes). The main reason for such a construction is to make the pipes flexible. Dry gas flowing across the cavities may generate high sound levels at some gas velocities. The high sound levels are both annoying and may cause vibrations with subsequent mechanical failures. No general mitigation technique has yet been found for this phenomenon, other than reducing the velocity and thereby the gas transport rate.

${ }^{1}$ IRPHE, CNRS-AMU-ECM , UMR 7342, Marseille, France

${ }^{2}$ ECM, Marseille, France, Corresponding author: anselmet@irphe.univ-mrs.fr

${ }^{3}$ NTNU, Acoustics Research Centre , Trondheim, Norway

${ }^{4}$ LMA, CNRS, UPR 7051, Marseille, France 
Therefore, the industrial problems caused by singing risers are the inspiration for the present research.

Our general objective is to study the sound producing mechanisms involved when gas is flowing in pipes having one or a system of small cavities [1]. Velocity measurements will, in particular, enable us to determine the modifications which are induced on the flow organization (in terms of coherent structures, turbulence levels, regions of most intense shear, ...). We aim at both understanding the origin of the noise generation, and then controlling it by acoustically generated oscillations that interfere with this and finally induce a significant reduction of the noise level or a shift in its peak frequency.

\section{Experimental set-up}

The whistling behaviour of a corrugated pipe is investigated through a dedicated experiment (Fig. 1a). A pipe of length $L_{\text {pipe }}=2 \mathrm{~m}$ and rectangular cross section $L_{c} \times L_{s}$, with $L_{c}=100 \mathrm{~mm}$ and $L_{s}=25 \mathrm{~mm}$ is inserted in the downstream part of the $\mathrm{S} 6$ IRPHE wind tunnel supplied by a low noise blower. The two opposite lateral walls occupying the long sides of the pipe section $\left(L_{c}\right)$ are regularly corrugated with square-section cavities of length $L_{c a v}=10 \mathrm{~mm}$ in the stream-wise direction and depth $D_{c a v}=10 \mathrm{~mm}$. The two opposite walls occupying short sides of the pipe section $\left(L_{s}\right)$ are smooth walls. The pitch-length, i.e. the space-period of the corrugations in the stream-wise direction, is $L_{p}=20 \mathrm{~mm}$. The pitch and cavity lengths are chosen such as $L_{p}=2 L_{c a v}$ The upstream edges of these cavities are rounded precisely with a radius $R_{c a v}=3 \mathrm{~mm}$. The corrugated vein is machined in transparent plexiglass for optical diagnostics use (PIV, LDA...). A wooden acoustic box is placed downstream the corrugated vein. Two loudspeakers (subwoofers, SONIC10MK2) are mounted face-to-face on this box in order to control the whistling of the corrugated pipe when working in phase. A long PVC (17m) pipe of $200 \mathrm{~mm}$ diameter is placed downstream the box in order to play the roll of a resonator. Two single hot-wires are used to characterise the flow velocity, the first one is located $5 \mathrm{~mm}$ upstream the vein entry and the other one is put downstream, inside the vein, $19 \mathrm{~mm}$ just upstream its exit section. The vein is also equipped with three microphones that measure the acoustic response of the system (Fig. 1b).

\section{Theoretical approach}

The sound emission by corrugated pipes in presence of a flow has been studied for quite a long time. A reference paper was proposed by Silverman [2] in 1989. More recently, Tonon \& al. [3] extended this study to multiple side branches system. 

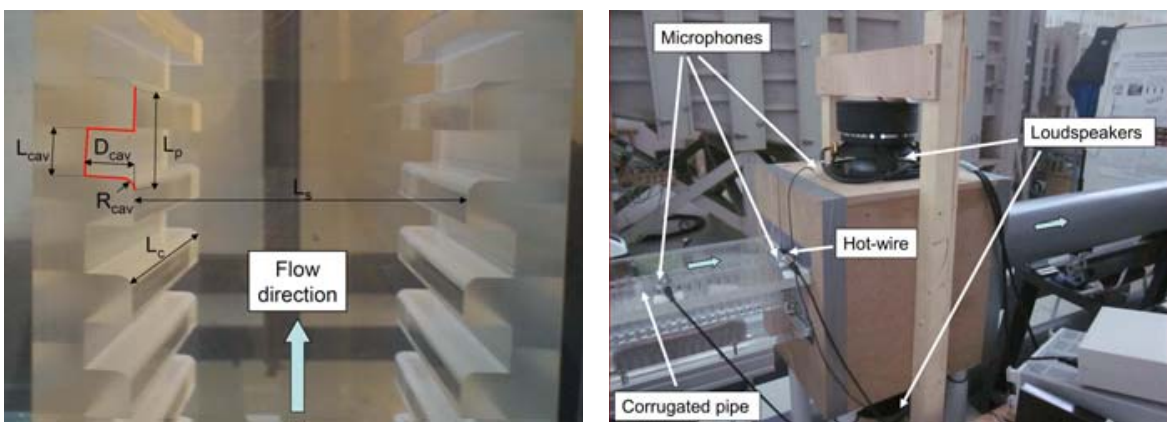

(a)

Fig. 1 Experimental set-up of the corrugated pipe. (a) Corrugation geometry and (b) aeroacoustics measurement techniques associated to the flow investigation.

This whistling noise occurs from a frequency coincidence between the longitudinal eigen-modes of the pipe and the oscillation of the fluid in the separated boundary layer that develops over the cavities constituting the pipe corrugations. The longitudinal eigen-frequencies of a corrugated pipe are not equal to the eigenfrequencies of non-corrugated pipe with the same length. The presence of the corrugation induces a reduction of the speed of sound waves in the pipe. An approximation for the eigen-frequencies of a corrugated pipe was proposed by Eliott [4]. It consists in considering the frequencies of the same pipe without corrugations but with a modified speed of sound $c_{\text {eff }}$ given by:

$$
c_{\text {eff }}=\frac{c_{0}}{\sqrt{1+V_{\text {cav }} /\left(S_{\text {pipe }} L_{p}\right)}}
$$

where $c_{0}=342 \mathrm{~m} . \mathrm{s}^{-1}$ is the speed of sound in air, at normal ambient pressure/temperature conditions, $V_{c a v}$ denotes the volume of the cavities contained between two sections of pipe separated by the pitch length $L_{p}, V_{c a v}=2 L_{c a v} D_{c a v} L_{c}$ and $S_{\text {pipe }} L_{p}=2 S_{\text {pipe }} L_{\text {cav }}$ is the volume of the pipe between two sections with distance of $L_{p}$. The efficient speed of sound for the pipe used in our experiment is then estimated as $C_{\text {eff }}=289 \mathrm{~m} \cdot \mathrm{s}^{-1}$. The evaluated eigen-frequencies of our corrugated pipe are consequently given by:

$$
f_{c}=n \frac{C_{\text {eff }}}{2 L_{\text {pipe eff }}}
$$

where $n=1,2,3, \ldots$, and $L_{\text {pipe eff }}$ is the effective pipe length that takes into the end correction at each end.

\section{Results}

The velocities of the flow measured at the vein exit are varied in the range 0$25 \mathrm{~m} \cdot \mathrm{s}^{-1}$. For the previously described arrangement, the whistling begins to be de- 
tected on upstream hot-wire signal at $16 \mathrm{~m} \cdot \mathrm{s}^{-1}$. The upstream hot-wire captures the pure tone of the oscillations while the turbulence that develops all along the corrugated pipe is superimposed to this sinusoidal oscillation on the downstream hotwire signal (Fig.2a). The response of the system in presence of a flow is checked to be in agreement with the predicted eigen-frequencies. The whistling is confirmed by both air velocity and pressure measurements where spectral analyses highlight peaks at frequencies associated to $6^{\text {th }}$ to $9^{\text {th }}$ modes as shown in figure $2 \mathrm{~b}$. As indicated by Lattice Boltzmann simulations of the flow over a single cavity [5], the noise emission occurring when a corrugated pipe is submitted to an internal flow of fluid is associated to the formation vortex. These vortex structures are convected downstream by the flow to the downstream edge of the cavity and contribute to give a non-null time averaged acoustic power.
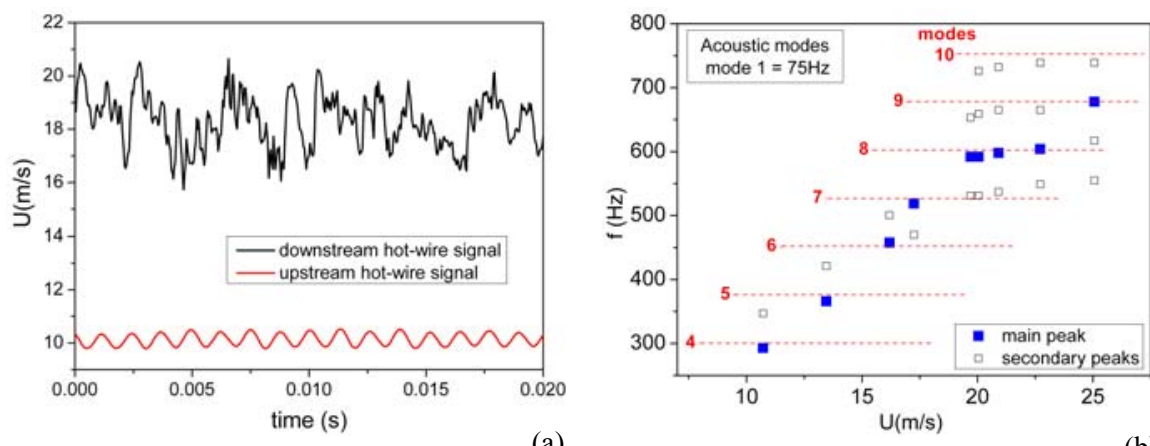

(a)

(b)
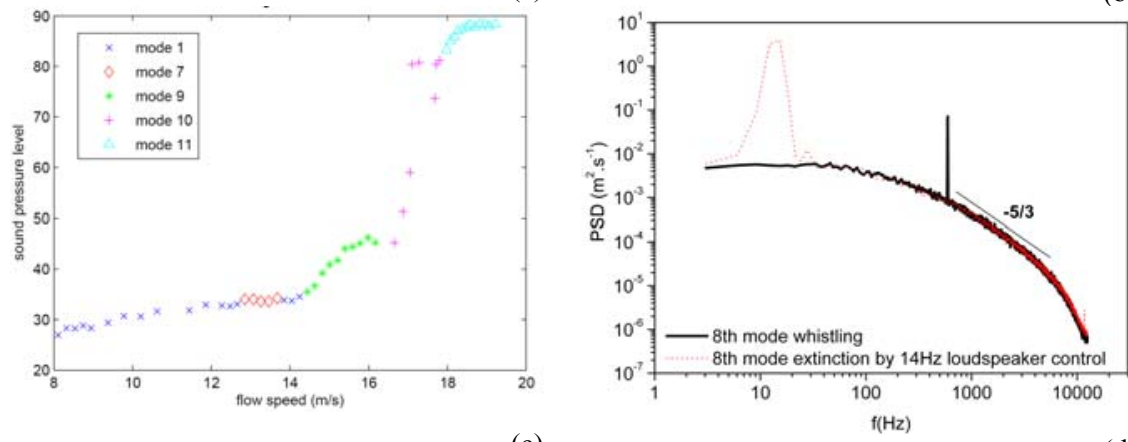

(c)

Fig. 2 Response of the corrugated pipe to an internal flow. (a) Velocity time series from hotwire, (b) Whistling frequencies with velocities, (c) Sound pressure levels (in dB) from microphone measurements, (d) Whistling control (extinction) by a low frequency sound.

In the range of velocity $20-25 \mathrm{~m} / \mathrm{s}$ measured by the downstream hot-wire, four modes were simultaneously detected with the spectral analysis of the upstream hot-wire signal. Above $17 \mathrm{~m} / \mathrm{s}$, only one strong mode is highlighted that is to be related to the sudden increase of sound pressure level as shown in figure $2 \mathrm{c}$. This pure tone was checked to be completely extinguishable by a low frequency signal emitted at $14 \mathrm{~Hz}$ by the two loudspeakers as shown on the downstream velocity 
spectral analysis, and without any obvious modification of the turbulence at the pipe exit (Fig.2d).
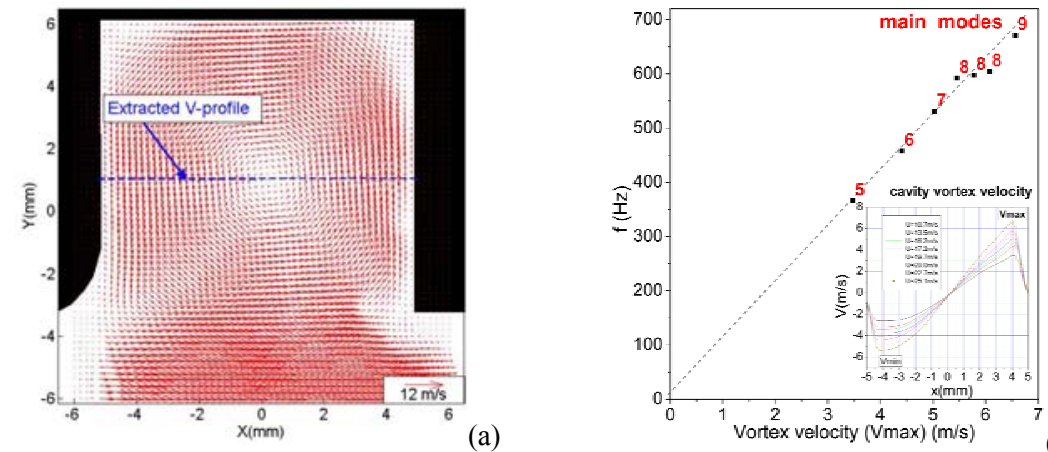

(a)

Fig. 3 Mean vortex in the cavity. (a) Velocity vectors measured by PIV, (b) Relation between whistling frequency (main modes) and vortex velocity inside the cavity: $\operatorname{Vmax} \approx L_{c a v} . f$.

\section{Conclusion - Perspectives}

This new experiment will be an interesting set-up for the aero-acoustics study of flow in a corrugated pipe as shown by the first comparisons between theoretical analysis and experimental results. The flow structure will be thoroughly investigated by PIV, in particular in the cavities where vortices are highlighted (Fig.3a and $b$ ). We plan to synchronize velocity snapshots with the pressure signal in order to analyse the vortex emission and its contribution to the corrugated pipe whistling. An associated numerical simulation is also developed for this purpose.

\section{References}

[1]. Kristiansen U. R., Mattei P.-O., Pinhede C., Amielh M.(2011) Experimental study of the influence of low frequency flow modulation on the whistling behavior of a corrugated pipe, J. Acoust. Soc. Am. 130(4): 1851-1855

[2] Silverman M.P., Cushman G.M. (1989) Voice of the dragon: the rotating corrugated resonator, European J. of Physics 10(4): 298-304.

[3] Tonon D., Landry B.J.T., Belfroid S.P.C., Willems J.F.H., Hofmans G.C.J., Hirschberg A (2010) Whistling of a pipe system with multiple side branches: Comparison with corrugated pipes. J. of Sound and Vibration, 329 (8), 1007-1024.

[4] Elliott J. W.(2005) Corrugated pipe flow, In Lecture Notes on the Mathematics of Acoustics, edited by M.C.M. Wrigth (Imperial College Press, London, 2005), 207-222.

[5] Kristiansen U., Mazzoni D., Krogvig A.B.(2012) Aeroacoustic investigation of a flow pipe with a small cavity using the lattice Boltzmann method, 35th Scandinavian Symposium on Physical Acoustics, Geilo, Norway. 